\title{
BEAUTY, UTILITY AND FUTILITY: THE ART OF CRAFT AND WHY WE CREATE
}

\section{Giles Panting}

"I don't get patchwork - you take perfectly good material, cut it up and then sew it back together again." This was the comment from an acquaintance - a fairly no-nonsense Yorkshireman - made sometime in early 2017 as part of a completely unrelated conversation. Because the comment came out of the blue, I didn't respond (or contest it) and the conversation continued to its conclusion. But that disconnected comment stayed with me. Why do I make things? Specifically, why am I, a middle-aged Englishman living in New Zealand, making textiles at a time in my life when I can afford to buy the things I make? And worse, much of my work over the last ten years has been created in the knowledge that I don't really want anyone to use the things I make.

Given that I have been mostly making quilts in the last decade, I have often considered whether what I have been making is art or craft. Can what I am making be considered art if its primary, albeit historical, purpose is everyday use? This is a question that was often on my mind during my years of producing ceramics - even the decision whether to write 'potter' or 'ceramic artist' on a census form entailed much philosophical angst and deliberation.

Of course, much has been written on that very subject, and while I have spent time considering that my quilts are one-off pieces, attempting to convey a concept or meaning of some sort, I always had the secret, nagging suspicion that the world at large would consider my work 'craft,' and that even the most indulgent art-literate friend would probably place my work at the low end of the 'high art-low art' continuum.

And so, being directed by a random comment to think about why it is that I do what I do - why I'm seemingly driven to create textile works that have, arguably, no mainstream artistic worth - has in turn led to a developing understanding of why I create what I create. It is helping me to understand my journey as a maker and as an artist.

I grew up in the rural south-west of England, mostly in the eighties. The world of the arts and crafts was flourishing and maturing into a plethora of colour and vibrancy following the wholesome brown ceramic glazes, hessian and idealistic self-sufficiency that the seventies embodied in my mind at the time.

My parents and grandparents were always making things. My father is a talented wood turner - historically the family trade (his father and grandfather were wood turners in the railway industry, as moulds for engine parts were created from wood masters or originals) - and potter. My mother had always sewn, but it was her quest to learn to spin that forms the most vivid memories from my childhood. My father made a beautifully turned wheel for her to learn on - the first of a collection of individually designed and handmade wheels - and her monthly guild meetings and regular trips to workshops, exhibitions and talks made an impression on me.

My grandfather was a cabinetmaker by training and trade; his workshop, at the end of a long garden, was an organised world of hard work and creation, while my grandmother was a knitter. To say that she was a knitter is an understatement. I struggle to remember a family event where she did not have her knitting to hand, and her ability to memorise complicated cable patterns and to knit, quickly and without looking while watching television or attending to a conversation, has stayed in my mind. 
Quite simply, I grew up in an environment where people made things. It wasn't done in a showy, "look at me, aren't I clever/artistic/amazing" way, it was just something that everybody did. Quietly and consistently things were made. Usually they were things that could be used: jumpers, socks, shirts, cushions, spinning wheels, furniture. But these items, made for everyday use, had integrity, and there was an unspoken understanding that they were made as well as they could be.

It was natural, then, that I should want to make things, to become a part of the tribe. My father's and grandfather's workshops were dangerous places - machinery, saws, sharp chisels and blades. And so, as a child, engaging in more domestic craft activities proved more accessible and so we learned to stitch, knit, weave. We were given materials, time and space - a converted attic space where we could make a mess in the pursuit of being creative.

I was possibly blessed by being one of the last generation of children who were allowed to be bored as a route to more interesting and imaginative activities. I've observed this in my own children when they were younger, as the first few days of the school holidays elicited cries of "I don't know what to do!" Push through this response, resist the urge to continually drive to a leisure centre or bowling alley and, given time, space and minimum materials, they will contrive to create the most amazing games, objects and worlds.

Ironically, given that my various careers have so far been involved in the world of education, it was the demand for a 'good education' in order to have a 'good career' that put paid to my creative endeavours. I continued to make things throughout my teenage years, but without the intensity and drive of my childhood. Teenage peer-pressure meant that making things became a largely furtive and potentially embarrassment-inducing activity.

\section{UTILITY}

I made my first quilt in 199I. I was in my first year of university and I wanted to make something. It had to be something that could be done with minimal equipment, space and in small amounts of time. I'd read Alice Walker's The Colour Purple, and Celie's formerly abusive husband, turning to sewing shirts in his old age, inspired me - here, at last, was a man who sewed. At that time I had also assumed that making a quilt would be less expensive than buying one ready-made.

That first quilt, still in existence and still in remarkably good condition, was simple - pale and tasteful hand-sewn squares quilted on a domestic sewing machine. It was followed by a second quilt, this one as bright and gaudy as the first was reserved. Made from recycled clothing, that quilt progressed with us through several family homes, on several beds and on to its final incarnation as a dog-quilt.

A gap of nearly two decades followed. Career, family, general grown-up real life and a move to New Zealand consumed my time and my years. And then, out of the blue, I suddenly found myself wanting to make a quilt. A utility quilt, to be used, abused and loved. And while making this quilt, I found myself reading about quilts - I discovered Nancy Crow and Gee's Bend and the gloriously joyful, vibrant quilts of Anna Williams. I wanted to make more, but I wanted them to exist as objects that were more than just something to keep us warm or look good on a bed. I found myself fascinated by the idea that quilts could contain meaning: messages that only made sense to those who knew the code - those who could read a quilt or a quilt block.

\section{BEAUTY AND ART}

And so I made a quilt inspired by a poem I'd read about the cremation of Frida Kahlo by George Young, The Cremation of Frida Kahlo. The poem describes her bones burning violet, and in the white ash that remained and a glowing red rod (which had been her spine).' 
The image of bones burned violet and then crumbling was an idea I wanted to explore. Using the New York Beauty block as a starting point (given the time that Kahlo spent in that city) seemed a reasonable idea constructed without too much concern over points and corners; spontaneity and chance seemed to suit the ideas I wanted to explore. By this time, I realised that I sought the irregular, the impulsive and the element of chance as a means to achieve a more lively and authentic piece of work. Good construction was important, slavish striving towards faultless technique was not. The jarring effect of slightly off-balance composition is appealing.

Images of violet bones and ash allowed me to explore a colour palette I would otherwise not have considered; a quote from Frida Kahlo's diary - "I hope that the end is joyful and I hope never to return" - is machineembroidered in a facsimile of Kahlo's handwritten entry. An incongruous block constructed of wild geese triangles points downwards, while a single black bird flies away from the bonds of the human body, never to return.

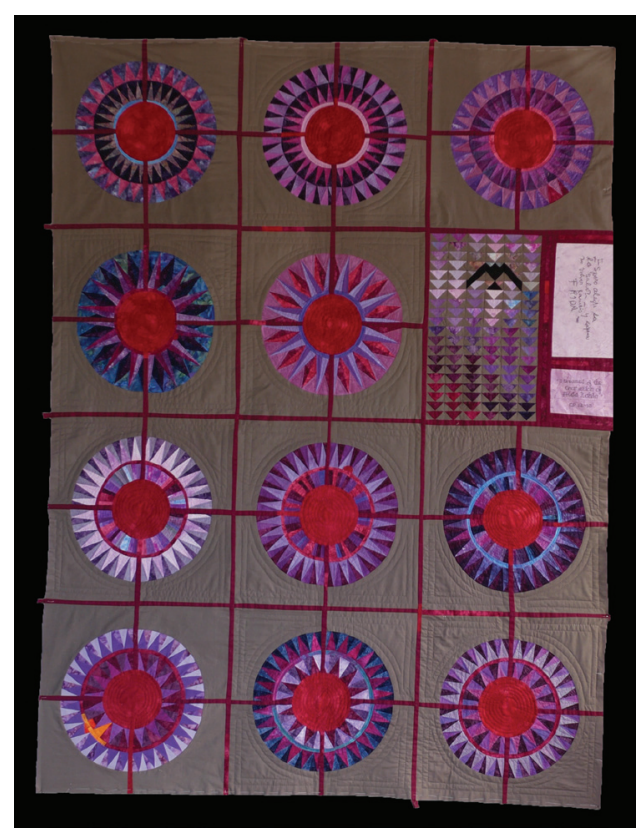

Figure I. Giles Panting, The Cremation of Frida Kahlo.

From 2012 to 2018 I worked, slowly and consistently, on a series of quilts, machine pieces and hand-quilted works that explored these ideas and techniques further. New techniques were learned, but not overlearned - I still value irregularity - and a free-form piece-cutting technique and associated ideas developed. The resulting series of four new quilts ended with a reworking of the original inspiration: The Artist, The Pain, Frida and Isamu (as Leda and the Swan) and The Cremation.
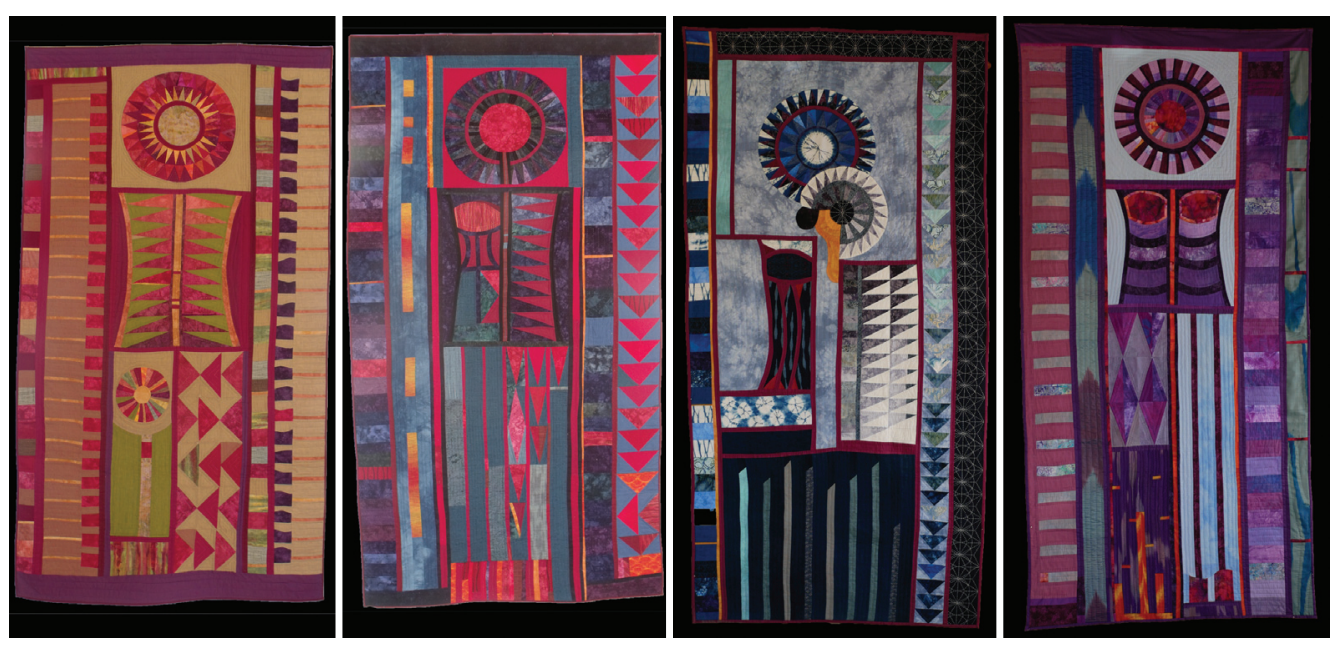

Figures 2-5. Giles Panting, The Artist; The Pain; Frida and Isamu (as Leda and the Swan); and The Cremation. 
Once an artist has a body of work, large or small, the question of exhibition arises. To exhibit or not to exhibit? Having said that, for me, creating quilts is a largely quiet, private occupation - there is an element of ego involved in seeing work displayed in a gallery. The first two quilts have been exhibited in the annual "Changing Threads" exhibition here in New Zealand, and the third was shown in an exhibition at the Rocky Mountain Quilt Museum in 20 I6. While I enjoyed seeing the two quilts hung, and properly lit, in a gallery environment, I have come to realise that external comment is not a key driver for me when considering why I make. It seems to matter less and less what other people think of my work the more I make. Positive comment is always a buzz; negative comment would not stop me making.

\section{FUTILITY}

Another period of creative inactivity (or redirection, really - smaller projects dictated by circumstance) was incurred by new jobs and two house moves, one of which was a new-build project. Once my new studio was set up and everything was unpacked and in its place, there was no excuse. And this is when the conversation from more than a year earlier started to dwell on my mind. Why was I making these quilts? What was the point? I was, after all, just cutting up material and sewing it back together again. The new studio contains plastic boxes and an antiques blanket box of the quilts that I have made, unused and unseen. There seemed to be an undeniable futility about what I spend so much of my time doing and thinking about.

Aware that starting the creative process is often the hardest part for me, I knew that I had to begin something. I also know from past experience that once I begin, the ideas flow and a sustained period of working ensues. Sewing anything at this stage is always more important than knowing exactly what will be produced.

I decided to celebrate the notion of futility in what I was doing as a way of continuing to understand why I make things. Starting with the idea of using "perfectly good material," I chose a length of raw silk, natural in colour - in this case, valuing my work through the inherent value of the cloth. I wanted to reference my earliest quilts by using a simple grid - in this case, either simple squares or squares made up of rectangles, triangles or smaller squares.

The arrangement as I stitched the cloth back together would be random, the design simple, geometric and understated, but quietly referencing the utility quilts from the past, made up out of necessity from squares of salvaged fabric. In essence, I was creating a ghost of a quilt from the past for an age when the object itself essentially, and arguably, has no place or purpose.

As a final reference to the handmade quilt's futile existence, I decided to add elements of darning where none was needed - large, circular darns in gold thread. My grandmother carefully darning hand-knitted socks is another childhood memory filed away - fine woollen yarn, in mossy, heathy colours from the local drapery.

I'd assumed, when starting, that this quilt would be the start of a new series. 'Real' artists, after all, work in sequence, exploring and developing ideas in multiple works. However, I think that this piece stands alone. It has helped me to understand where my current work sits in terms of what has come before and what might come after.

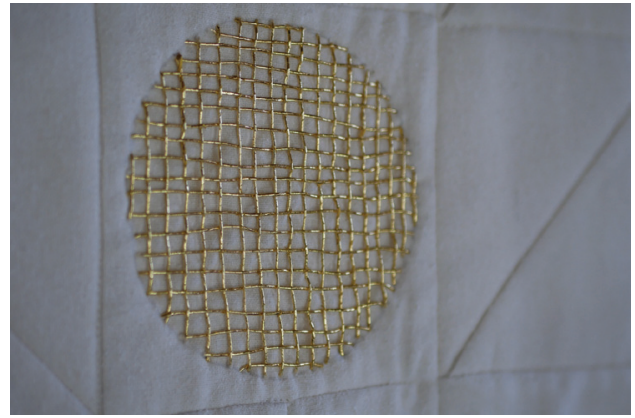

Figure 6. Giles Panting, A Study of Futility in Utility. 


\section{THE WORK OF CRAFT}

And so, my work as a quilter having (almost) come full circle, I am free to accept that whether what I create is considered art or craft actually doesn't matter to me as much as I thought it did. There is no real validation necessary to be sought in the opinions of the viewer, however expert in the field. The chance comment of an acquaintance, in inviting me to consider the 'why' of making, rather than categorising the 'what,' has inadvertently freed me. I understand that my drive to create - whether rooted in early familial experiences, whether innate or learned - is here to stay.

As I write this in my studio, I am surrounded by fabrics (mostly in shades of red for current work) and pieces of quilts in progress. I will probably always make quilts that I intend to be used - to be loved, thrown in the washing machine, looking better for each year of use and misuse (the memory of quilt-tents in the orchard on sunny afternoons is definitely better than recollections of a perfectly preserved quilt). I will probably also always make quilts that exist 'just because.'They are the quilts that might try to express something deeper - who knows?

Working on the pale, monochromatic Futility quilt awoke the dormant need for colour and improvisation in quilt making. At the moment, I am enjoying cutting fabric into shapes and piecing them together. The completely red quilt that I have been planning in my mind looks as though it will end up with flashes of turquoise and egg-yolk yellow! l've learned not to fight it.

Born in England, Giles Panting emigrated to New Zealand in 2006. Working full-time in education (as principal of a primary school and currently as manager, Professional Learning and Development, for the Ministry of Education), I seek to maintain a healthy work-life balance through my practice as an artist working primarily in textiles.

I George Young, "The Cremation of Frida Kahlo," The Pharos (summer 2007), https://alphaomegaalpha.org/pharos/AOAThePharos-Summer2007.pdf. 